\title{
LA JORNADA DE TRABAJO \\ - FLEXIBILIZACIÓN Y DESREGULACIÓN, BREVE REFERENCIA AL CASO ESPAÑOL -
}

José Cervantes Herrera*

Sumario:

I. Introducción. II. Marco de Referencia de la Jornada de Trabajo. III. La Norma Laboral Internacional. IV. La Constitución y la Jornada de Trabajo. V. La Jornada de Trabajo. VI. La Jornada de Trabajo en el Contexto de la Flexibilización y de la Desregulación. VII.Propuestas. VIII. Conclusiones.

Resumen. En el Derecho del Trabajo, la jornada es una de las condiciones más sensibles a la globalización, particularmente a la tendencia para flexibilizar y desregular determinadas condiciones de trabajo, a través de la vía legislativa o mediante los contratos o convenios de trabajo, a partir del argumento de la productividad y la competitividad de las empresas en los mercados nacional e internacional, respectivamente. Un referente, para nosotros cercano, y que refleja la tendencia para flexibilizar y desregular, particularmente la jornada de trabajo, es el sistema jurídico laboral español, que nos ilustra sobre la manera como esa tendencia se materializa y que nos ofrece la oportunidad de la reflexión sobre lo que pudiera ocurrir en México.

Palabras clave: jornada de trabajo, flexibilización, desregularización.

Abstract. The law that protects the hours of daily work is very sensitive to the globalization, especially because nowadays there is a pattern for the flexibility and deregulation of certain conditions of work. Through the legislative process or by means of contracts, using productivity and competence criteria, the corporations at the national and international level are trying to do that. For us, there is an example to make flexible and deregulate the hours of work, it is the Spaniard system, which offers to us an opportunity to see what could happen in Mexico.

Keywords:Law, work, flexibility, deregulation, journey, schedule, system, hours.

\section{INTRODUCCIÓN}

La globalización se ha convertido en un tema de análisis obligado en el ámbito académico, por su incidencia en diversos escenarios de la ciencia.

La globalización o mundialización, como también se denomina, ha profundizado la interdependencia económica social, cultural y política de todos los países del mundo hoy en día, en mayor o menor medida, los países participan en un inusitado comercio de bienes y de servicios, así como en el flujo de capitales, merced al avance de los medios de transporte y del

* Profesor de la División de Derecho, Política y Gobierno de la Universidad de Guanajuato. 
uso de las nuevas tecnologías de información y comunicación. Es tal la importancia de estos cambios, que ha provocado el surgimiento de un nuevo continente sin tierra, en el cual las fronteras convencionales prácticamente han desaparecido.

El derecho no es ajeno ni independiente de las reorganizaciones que provoca la globalización. El derecho tiene ante sí el reto de decifrar y comprender en su real sentido, la redefinición del papel del Estado, la reactualización de la sociedad, las nuevas formas de los procesos de trabajo, las modificaciones en la estructura familiar, la urgencia de introducir celeridad y oportunidad en todos los órdenes, etc.

Uno de estos retos del derecho, tiene que ver con el derecho del trabajo, como instrumento que regula las condiciones de trabajo, individuales y colectivas, que sin duda por su naturaleza, es altamente vulnerable a este vasto conjunto de transformaciones jurídicas, políticas, económicas y epistemológicas que en la actualidad recorren el mundo como una ola inmensa que amenaza con destruir o por lo menos, modificar la concepción tradicional de los sistemas jurídicos.

Dentro del derecho del trabajo, la jornada de trabajo es una institución sensible a este complejo panorama de profundas transformaciones, tanto por los cambios en los procesos de producción, en la actividad económica, en la estrategia patronal o empresarial y en el comportamiento de las organizaciones sindicales.

Considerando lo anterior, el presente trabajo tiene como objeto el análisis de la jornada de trabajo, como condición o institución central del derecho del trabajo, y de las presiones que sobre ella ejerce la globalización, particularmente en la pretensión de su flexibilización y desregulación, con la finalidad de que los procesos económicos y de producción en el esquema de globalización, tengan escenarios jurídicos favorables y para conciliar los intereses de empresarios y organizaciones de trabajadores. El análisis, se particulariza al modelo vigente en España, a partir de la Constitución y de la Legislación, como ejemplo normativo de la desregulación y flexibilización de la jornada de trabajo.

\section{MARCO DE REFERENCIA DE LA JORNADA DE TRABAJO}

\section{II.1. EN LA Historia}

Como lo señala Palomeque López y Álvarez de la Rosa, ${ }^{1}$ la jornada como sucede con el salario, aparece como elemento esencial del contrato, como 
objeto de las obligaciones que, según lo predicable de todo contrato, ha de ser cierto (art. 1.261, $2^{\circ}$ Código Civil). En un contrato de duración como el de trabajo, constituyen posiciones jurídicas básicas del trabajador saber que y cuanto trabajo ha de dar; del empresario saber cuanto dinero recibe en trabajo.

En este orden de ideas, De la Cueva ${ }^{2}$ indica que el derecho del trabajo se inicia desde el primer momento, con dos aspiraciones de los trabajadores: la reducción de la jornada de trabajo y el aumento de los salarios.

La reducción de la jornada de trabajo fue, durante más de un siglo, una de las reivindicaciones más constantes de los trabajadores; el movimiento se inicio, afirma Válticos, ${ }^{3}$ en el siglo XIX en los países europeos en que con la naciente industrialización, no era raro que los periodos de trabajo durasen de catorce a dieciséis horas.

En la antigüedad, no podía hablarse propiamente de reglamentación del trabajo, porque predominaba la esclavitud. En la Edad Media, donde rige el sistema corporativo, aparece una limitación incipiente de la jornada, al circunscribirse ésta al trabajo efectuado de "sol a sol" con descanso al medio día. No se trabaja de noche, y las arduas jornadas quedaban atenuadas por el hecho del gran número de días festivos, de que los sábados y vísperas de días feriados, en que se trabaja sólo media jornada. Durante ésta época como lo refiere Hernández Rueda, ${ }^{4}$ la limitación de la jornada tenía por objeto impedir la producción de artículos de mala calidad y, por ende, atendía más al interés del patrón que a la conservación de la salud de los trabajadores o a la humanización de las condiciones de trabajo.

Pasando por alto la referencia a ciertos antecedentes históricos de la jornada máxima de ocho horas (como la establecido en las Leyes de Indias para el trabajo en las fortalezas y construcciones militares), las jornadas realmente extorsivas, como las llama Alfredo Palacios, ${ }^{5}$ nacieron con el régimen capitalista industrial, tal consecuencia surgió por la libertad de contratación, ya que al no existir reglamentación alguna, respecto a la duración del trabajo, la parte débil y requerida de cualquier trabajo para subsistir, quedó a merced del desenfrenado deseo de ganancia y de la favorecida posición de los empresarios. El número creciente de obreros, contribuyo a agra-

\footnotetext{
${ }^{2}$ De la Cueva, Mario, Derecho del Trabajo, tomo I, Editorial Porrúa, México, 1938, p. 488.

${ }^{3}$ Válticos, Nicolás Derecho Internacional del Trabajo, Editorial Tecnos, Madrid, España, 1977 p. 314.

${ }^{4}$ Hernández Rueda, Lupo, Derecho Latinoamericano del trabajo, Baltasar, Cavazos Flores Compilador, Editorial Trillas, México, 1981, p. 379.

${ }^{5}$ Palacios, Alfredo, La Fatiga, p. 248, citado por Efrén Cordova Cordovés, Derecho Laboral Cubano, Editorial Lex, Vol. I, La Habana, Cuba, 1957, p. 238.
} 
var la situación, llegándose a laborar en muchas ciudades europeas jornadas promedio de dieciséis horas.

Esta situación de explotación de los obreros, en opinión de Gallard, ${ }^{6}$ conmovió profundamente la conciencia social y ya desde los inicios del régimen de la Gran Industrialización, comienzan a producirse las protestas de reformadores como Roberto Owen, y luego, cuando el espíritu de clase y la personalidad colectiva de los afectados se desarrolla, surgen los acuerdos de distintos Congresos obreros que desde mediados del siglo XIX, se inscriben entre sus reivindicaciones fundamentales la del límite de las ocho horas, diarias a ese proceso de peticiones, agrega; debe añadirse la influencia de la iglesia por León XIII, que en la Encíclica Rerum Novarum, hizo constar que exigir tan grande tarea, con el excesivo trabajo se embote el alma y sucumba al mismo tiempo el cuerpo a la fatiga, ni la justicia ni la humanidad lo consientan.

Camerlinck y Lyon - Caen, ${ }^{7}$ consideran que la reducción de la jornada ha sido posible gracias a diversos factores ideológicos (así, el Marxismo explica el origen del beneficio capitalista debido a la prolongación del trabajo más allá del tiempo necesario para que el asalariado asegure sus necesidades vitales; técnicos (únicamente el progreso de la técnica ha producido lo mismo en menos tiempo, manteniendo la remuneración anterior del asalariado, condición sin la cual el progreso será ilusorio).

Todo ello conduce, inevitablemente, a la intervención del Estado para regular de manera imperativa esta cuestión, lo que tiene su primera manifestación en un decreto francés del 2 de mayo de 1848, que fija el límite de la jornada en diez horas en París y once en las provincias, y alcanza después en otros países progresivos reducciones hasta que finalmente en el tratado de Versalles, se consigna con carácter internacional el principio de la jornada de ocho horas.

El tratado de Versalles, en opinión de De la Cueva, ${ }^{8}$ es fruto de un estudio meditado, que constituye un paso positivo a favor del derecho internacional del trabajo; es así que el Preámbulo de la parte XIII del mencionado tratado, dice:

"Considerando que existen condiciones de trabajo que implican para un gran número de personas la injusticia, la miseria y las privaciones, lo que, a su vez, origina tal descontento que la paz y armonía universales es-

\footnotetext{
${ }^{6}$ Gallard Folch Alejandro, Derecho Español del Trabajo, Editorial Labor, Barcelona, España, 1970, p. 241, tomo 384-385 de la Sección VIII, Ciencias Jurídicas, Colección Labor.

${ }^{7}$ Camerlinck y Lyon - Caen, Derecho del Trabajo, Editorial Aguilar, Madrid, España, 1974, p. 158

${ }^{8}$ De la Cueva, Mario, op. cit. p. 224.
} 
tán en peligro, es urgente mejorar esas condiciones, como, por ejemplo, la reglamentación de la jornada diaria y semanal de trabajo, el reclutamiento de la mano de obra, la lucha contra el paro, un salario que garantice condiciones convenientes de existencia, las enfermedades generales o profesionales y los accidentes de trabajo, la protección de los menores, de los niños y de las mujeres, las pensiones de vejez e invalidez, la defensa de los intereses de los trabajadores que se encuentren en el extranjero de afirmación del principio de la libertad sindical, la organización de la enseñanza, profesional y técnica y otras medidas análogas".

El Preámbulo, en opinión, unánime de los tratadistas, contiene un mínimo de garantías, sin que la acción internacional deba limitarse, pues la frase final indica que se trata de una enunciación, más no de una limitación.

Además del Preámbulo, el artículo 427 del tratado de Versalles, en el que se señala de manera expresa en el punto 4, "la adopción de la jornada de ocho horas o de la semana de cuarenta y ocho horas, tiene como fin a alcanzar, ahí donde aún no se hubiere obtenido".

Otro antecedente, lo constituye la Primera Conferencia Internacional, organizada por la Organización Internacional del Trabajo en Washington en 1919, que mediante el Convenio número 1, limita la duración del trabajo a ocho horas diarias y a cuarenta ocho horas por semana en las empresas industriales. En 1930, la propia OIT, adoptó un convenio relativo a la jornada de ocho horas diarias y cuarenta y ocho horas semanales, para el comercio y las oficinas.

Válticos, ${ }^{9}$ considera que nuevos métodos de producción y la crisis de los años de treinta, produjeron la reducción de la jornada de trabajo en América y Europa, y la introducción de la semana de cuarenta y cuatro o cuarenta y cinco horas, con cinco días de trabajo. En 1935, tras difíciles debates, la OIT adoptó el Convenio número 47, afirmando simplemente el principio sobre instrumentos separados de las cuarenta horas, debían reglamentar la aplicación en diversos sectores: industria siderúrgica, la construcción, minas de carbón, industrias químicas e imprenta; pero fracaso en los relativos a las minas de carbón, comercio, oficinas, entre otras.

Tras la segunda guerra mundial y el periodo de la reconstrucción, la cuestión de la reducción del trabajo a cuarenta horas por semana, volvió a plantearse una vez más. Un primer proyecto de recomendación en 1961, no pudo conseguir la mayoría relativa, pero la Conferencia adoptó al año si-

${ }^{9}$ Válticos Nicolas, op. cit. p. 317. 
guiente, una recomendación, la número 116, que preveía la reducción progresiva de la duración semanal del trabajo a la norma social cuarenta horas.

La actividad normativa de la OIT, en el terreno de la duración del trabajo es encomiable, basta referir los convenios y recomendaciones más relevantes:

Convenios: números 1 en 1919; 30 en 1930; 47 en 1935; 51 en 1936; 57 en 1936,61 en 1939,76 en 1946; 93 en 1949 y 109 en 1958.

Recomendaciones: números 7 en 1920; 8 en 1920; 37 en 1930; 38 en 1930; 39 en 1930; 49 en 1936; 65 en 1939; 66 en 1939; 109 en 1958.

Palomeque López y Álvarez de la Rosa ${ }^{10}$ afirman que la lucha histórica por la disminución de la jornada de trabajo, está inscrita en los orígenes y en el desenvolvimiento del movimiento obrero organizado y constituye siempre una muestra de las primeras manifestaciones del Estado, en su labor de integración del conflicto que genera el trabajo por cuenta ajena. Sobrepasan ya el siglo las intervenciones del legislador en materia de jornada. Entre la Ley Benot de 24 de julio 1873 y la Ley II/1994, de 19 de mayo, de modificación del Estatuto de los Trabajadores, hay hitos legislativos que jalonan la historia de la reducción del número de horas en el trabajo por cuenta ajena. Disminuir, proteger la integridad física o moral del trabajador, se configura como una reivindicación colectiva resulta sobre todo por la intervención del Estado, pero con la colaboración de la negociación colectiva.

En la actualidad, tal vez asunto de la disminución de las horas de trabajo, se desplace hacia la mejor distribución del tiempo ocupado, configurando el trabajo de lunes a viernes y la jornada continúa. Por otra parte, el horario flexible y la redistribución de la jornada en diversas épocas del año, constituyen un nuevo modelo de administración del trabajo, alejándose de las jornadas a tiempo completo y uniformes. En este contexto se ubican algunas reformas al Estatuto de los Trabajadores, a las Directivas de la Unión Europea y el Acuerdo Interconfederal para la Estabilidad del Empleo.

\section{II.2. En la Doctrina}

Por tratarse de una institución central del derecho del trabajo, la jornada tiene una amplia atención por la totalidad de la doctrina, particularmente, en cuanto a su concepto.

${ }_{10}$ Palomeque López, Manuel Carlos y Álvarez de la Rosa, Manuel, op. cit. p. 860. 
Para Montoya y Melgar, ${ }^{11}$ la actividad laboral, como cualquier otra, se desenvuelve en el tiempo y, concretamente, en el tiempo diario al que se le da el nombre de jornada del trabajo. El número de horas que componen esta jornada laboral, se fija de modo más o menos científico y preciso, de acuerdo con criterios de naturaleza económica, técnica e institucional.

Desde el punto de vista económico, es esencial en la determinación de una jornada mínima, a efecto de que el trabajador obtenga un salario para satisfacer sus necesidades naturales, pero también, para que el empresario pueda financiar su empresa y obtener beneficios. Desde el punto de vista técnico, debe considerarse el menor o mayor grado de automatización de las empresas e industrias y, desde el puno de vista institucional, el mayor o menor sentido social del Estado y de la presión de los sindicatos.

En este sentido, Ballester Hernández, ${ }^{12}$ es coincidente al decir que los fundamentos de la jornada, son razones que podrían llamarse, globalmente: a) de carácter humanitario, entre las cuales incluye las relativas a la preservación de la salud, las referencias a permitir la vida familiar y cívica del trabajador, y los razonamientos jurídicos; b) de carácter económico, entre las que coloca las referentes a la productividad y las que ven en la limitación de la jornada, una manera de combatir la desocupación.

García Ortega y otros tratadistas, ${ }^{13}$ estiman que en virtud del contrato de trabajo, el trabajador asume entre otras, la obligación de prestar sus servicios bajo la dirección del empresario. Ahora bien, dado que el contrato del trabajo es de ejecución continuada, resulta preciso concretar los periodos de tiempo durante los cuales el trabajador deba satisfacer su prestación laboral. En este sentido, existe una línea de tendencia histórica a limitar esos períodos por la vía de establecer una duración máxima de la jornada laboral. Y en este sentido, señalan que la jornada ordinaria de trabajo es el tiempo que cada día, semana o año dedica el trabajador a la ejecución de la prestación del trabajo.

Martín Valverde ${ }^{14}$ considera que toda vez que la regulación de la duración máxima de la jornada en el ordenamiento español, es el resultado de la

\footnotetext{
${ }^{11}$ Montoya y Melgar, Alfredo, Derecho del Trabajo, Editorial Tecnos, Madrid España, 2002, p. 342.

12 Ballester Hernández, Antonio, Lecciones de Derecho del Trabajo, Universidad Autónoma de Santo Domingo, República Dominicana, 1977, p. 94.

${ }^{13}$ García Ortega Jesús y otros, Curso de Derecho del Trabajo, Editorial Tirant lo Blanch, Valencia, España, 2001, p. 343.

${ }^{14}$ Martín Valverde, Antonio, Rodríguez, Sañudo Gutiérrez, Fermín y García Murcia, Joaquín, Derecho del Trabajo, Editorial Técnos, Madrid, España, 2002, p. 548.
} 
articulación de las normas estatales y de los contenidos en los convenios colectivos. Por tanto, la idea básica de la regulación legal es, como quedó indicado la de establecer una duración máxima del tiempo de trabajo, en distintas unidades de computo.

Para Alonso Olea y Casa Baamonde, ${ }^{15}$ por jornada de trabajo se entiende el tiempo que cada día - pese a lo incorrecto de la expresión -, cada semana o cada año ha de dedicar el trabajador a la ejecución del contrato de trabajo; el tiempo del trabajo diario, semanal o anual. Como, según se dijo, lo que el trabajador debe, no es realmente un tiempo de trabajo, sino el trabajo prestado durante un cierto tiempo, se supone que la jornada se invierte en un trabajo efectivo y real y, en tal sentido, la jornada es una primera aproximación para medir la prestación que el trabajador debe.

\section{LA NORMA LABORAL INTERNACIONAL}

\section{III.1. Los Pactos y Convenios Internacionales}

Los pactos o convenios internacionales, son por excelencia la manifestación más objetiva de la vida de relación de los miembros de la comunidad internacional, pueden ser considerados, en un sentido amplio, como los acuerdos entre dos o más estados para crear, para modificar o para extinguir una relación jurídica entre ellos.

La globalización, en algunas regiones del mundo como en la Unión Europea, los pactos o convenios internacionales suelen tener importancia y trascendencia entre los países firmantes, por cuanto se constituyen en instrumentos normativos regulatorios de una diversidad de materias.

En el caso de España, es conveniente distinguir entre normas internacionales, propiamente dichas, y normas de derecho internacional y de sus organismos especializados. Los actos de expresión de esta capacidad normativa son los tratados, convenios o acuerdos internacionales, que pueden ser bilaterales o multilaterales. Dentro de este contexto, tienen un lugar destacado los Convenios de la Organización Internacional del Trabajo.

Respecto de los tratados internacionales, el artículo 96, de la Constitución Española, señala que, los tratados internacionales validamente celebrados, una vez publicados oficialmente en España formarán parte del ordenamiento interno. Sus disposiciones sólo podrán ser derogadas, modi-

\footnotetext{
${ }^{15}$ Alonso Olea, Manuel y Casas Baamonde, Emilia, Derecho del Trabajo, Editorial Civitas, Madrid España, 2001, p. 265.
} 
ficadas o suspendidas en la forma prevista en los propios tratados o de acuerdo con las normas generales del Derecho Internacional. Por su parte el artículo 1.5 del Código Civil Español, indica que la publicación íntegra de las normas contenidos en los tratados internacionales, lleva consigo su aplicación directa en España, cuando sean autosuficientes, es decir, cuando no necesitan para su aplicación o puesta en práctica de normas complementarias o de desarrollo.

Como lo apunta Martín Valverde ${ }^{16}$ la prestación del consentimiento del Estado en los tratados o convenios internacionales en cualquier materia incluida la laboral, no siempre requiere previa autorización de las Cortes Generales. Pero tal autorización es precisa en los supuestos de tratados o convenios que supongan modificación o derogación de alguna ley o exijan medida legislativa para su ejecución, conforme a lo dispuesto por el artículo 94.1.e de la Constitución Española.

En este escenario, los pactos internacionales, en general, tienen eficacia diversa, en ocasión son meras declaraciones políticas sin carácter obligatorio alguno, como por ejemplo: La Declaración Universal de los Derechos Humanos de 1948; o bien suponen mayores o menores obligaciones de informar a los organismos respectivos, por ejemplo: la Carta Social Europea; o bien, incluso llegan a prever verdaderas actuaciones judiciales con posibilidad de sentencias condenatorias para los Estados infractores, como el caso del Convenio Europeo, a través de la actuación del Tribunal de Derechos Humanos de Estrasburgo.

Con todo, como lo dice Palomeque López, Manuel Carlos y Álvarez de la $\operatorname{Rosa}_{,}{ }^{17}$ la norma internacional posee una función constitucional de extrema importancia para el sistema español, en la medida en que es llamada por la propia Constitución, bajo determinadas presupuestos, para contribuir a la determinación de los derechos y libertades constitucionales, así, las normas relativas a los derechos fundamentales y a las libertades que la Constitución reconoce, se interpretarán de conformidad con la Declaración Universal de Derechos Humanos y los tratados y acuerdos internacionales sobre las mismas materias, ratificados por España, conforme a lo dispuesto por el artículo 10.2 de la Constitución Española.

\footnotetext{
${ }^{16}$ Martín Valverde, Antonio, op. Cit. P. 96.

${ }^{17}$ Palomeque López Manuel Carlos y Álvarez de la Rosa, Manuel, op. cit. p. 312.
} 
En consecuencia, siguiendo la posición de Rodríguez - Zapata, ${ }^{18}$ el tratado internacional es una fuente autónoma del Derecho en la Constitución Española de 1978. Se puede afirmar la relevancia constitucional de los tratados internacionales, como mecanismos productores de normas jurídicas en la esfera internacional que, al mismo tiempo, tienen plena validez y eficacia en el ordenamiento interno.

El tratado internacional es norma jurídica interna, como resultado o producto de la fuente de que emana. Es posible, en fin, que el tratado internacional se convierte en fuente de fuentes del derecho, con la consecuencia de que por tratado, se puedan establecer nuevos mecanismos de producción de normas jurídicas, que se añaden a los previstos en la Constitución.

Por tanto, todos los tratados internacionales, formarán parte del ordenamiento jurídico interno, conforme al principio Pacta Sunt Recipienda. Pero, además, de forma automática.

Tan es así que, la Sentencia del Tribunal Constitucional 254/1993, de 20 de julio, ha reconocido que ante el retraso del legislador en desarrollar el artículo 18.4 de la Norma Fundamental sobre la protección de los ciudadanos frente a los abusos de la informática, el artículo 8 del Convenio del Consejo de Europa para la protección de las personas con respecto al tratamiento automatizado de datos de carácter general, hecho en Estrasburgo el 28 de enero de 1989, es suficiente para reconocer el derecho a obtener información y desarrollar un derecho fundamental reconocido en la Norma Fundamental.

Como se ha dicho, el Derecho Español establece un mecanismo de incorporación automática de los tratados internacionales. El acto de conclusión de un tratado o acuerdo internacional en la esfera internacional es, al mismo tiempo, un acto interno de perfeccionamiento del tratado como fuente del Derecho Español, una vez que se ha publicado en el Boletín Oficial del Estado.

La posición de los tratados internacionales, en el sistema de fuentes del Derecho Español, es una cuestión debatida en la doctrina, aún cuando prevalece una corriente de opinión, derivada de la sentencia de la Sala Cuarta del Tribunal Supremo de 27 de febrero de $1970,{ }^{19}$ a cuyo tenor los tratados o convenios internacionales tienen primacía, en caso de conflicto o contradicción con las fuentes del derecho interno que pudieran diferir de lo estipulado.

\footnotetext{
${ }^{18}$ Rodríguez Zapata, Jorge, Teoría y Práctica del Derecho Constitucional, Editorial Tecnos, Madrid, España, 1996, p. 191.

${ }^{19}$ Citada por Rodríguez - Zapata, op. cit. p. 193.
} 
En este rubro de pactos o convenios internacionales propiamente dichos, caben los siguientes:

a) Los convenios de carácter multilateral elaborados y adoptados por la Organización Internacional del Trabajo y hayan sido ratificados por España.

Dentro de los Convenios de la OIT, ratificados por España, sobresalen los números 87 y 98 sobre libertad sindical; 95 sobre protección al salario; 97 relativo a los trabajadores migrantes; 132 sobre vacaciones anuales pagados; 138 sobre edad mínima de admisión al empleo y 140 relativo a la licencia pagada de estudios.

b) Pactos o Convenios Internacionales con otras organizaciones:

b.1. Pacto Internacional de Derechos Civiles y Políticas, ratificado en 1977, que contiene interesantes aspectos laborales como la no discriminación, el derecho de libre asociación, etc.

b.2. Pacto Internacional de Derechos Económicos, Sociales y Culturales, ratificado en 1977, que refiere importantes cuestiones en materia laboral, como: el derecho al condiciones de trabajo equitativas y satisfactorios, el derecho a la seguridad social, la libertad sindical y el derecho de huelga, entre otros.

b.3. Convenio Europeo para la Protección de los Derechos Humanos y de las Libertades Fundamentales, ratificado en 1979, que proclama el derecho de fundar sindicatos, derecho a no ser discriminado, entre otros.

b.4. Carta Social Europea, ratificada en 1980, que reconoce los derechos individuales y colectivos al trabajo, la seguridad e higiene en el trabajo, la remuneración equitativa, la negociación colectiva, la protección de jóvenes y mujeres trabajadoras, seguridad social, derecho a la capacitación, protección de migrantes y minusválidos, entre otros.

c) Los tratados bilaterales, que España tenga celebrados con otros países. 


\section{III.2. La Unión Europea}

Es importante distinguir de los pactos o convenios internacionales, las normas de Derecho Comunitario Europeo, que son elaborados con sus reglas específicas de producción normativa, en el seno de una comunidad supranacional - la Comunidad Europea - cuya prolongación en el ámbito político ha formado la Unión Europea desde el acuerdo de Maastricht a la que España pertenece desde 1986. Asimismo, es menester distinguir entre fuentes de derecho derivado en el Derecho Comunitario. Dentro de las fuentes de derecho originario figuran los tratados internacionales, como el tratado constitutivo de la Comunidad Europea, cuya versión inicial se aprueba en Roma el 25 de marzo de 1957; el tratado y el acta de adhesión de Portugal y España de 12 de junio de 1985; el acta Única Europea suscrita el 17 y 28 de febrero de 1986; el acuerdo de Maastricht o tratado de la Unión Europea de 7 de febrero de 1992 y el tratado de Ámsterdam de 2 de octubre de 1997, ratificado por España en 1998. Estas fuentes de derecho originario se inscriben en el contexto de los tratados internacionales que hemos desarrollado en el punto anterior de este trabajo.

El derecho derivado de la Comunidad Europea resulta del ejercicio de las competencias normativas atribuidas a las instituciones comunitarias. Estas fuentes de derecho derivado, subordinadas jerárquicamente al derecho originario, pueden adoptar tres modalidades, conforme al artículo 249 del Tratado Constitutivo de la Comunidad Europea: el Reglamento, la Directiva y Decisión:

a) Los Reglamentos son disposiciones de carácter general, cuyos destinatarios en cuestiones laborales pueden ser, aparte de las administraciones públicas, las empresas y los trabajadores. Son obligatorios y directamente aplicables en los Estados, sin necesidad de desarrollo ni de publicación de los mismos en los diarios oficiales respectivos.

Su utilización en materia laboral se ha limitado a la regulación de la libre circulación de trabajadores asalariados y de la seguridad social de los trabajadores por cuenta propia y ajena.

b) Las Directivas son disposiciones obligatorias, pero sus destinatarios son los Estados miembros, que quedan obligados a alcanzar los objetivos en ellas señalados, con mayor o menor concreción, aunque gozan de un margen de discrecionalidad para concretar los medios adecuados a tales fines. 
Por lo tanto, no son directamente aplicables, sino que necesitan de su transposición en el plazo previsto. No obstante el Tribunal de Justicia de las Comunidades Europeas ${ }^{20}$ admite la eficacia directa de una directiva, siempre que su contenido sea suficientemente concreto y haya transcurrido el plazo para su desarrollo. Pero tal eficacia directa supone exclusivamente que dejarán de ser aplicables las normas internas contrarias a la directiva. Por otra parte, salvo que se desarrollen, las directivas no suponen obligaciones entre particulares, como empresas y trabajadores.

La utilización de las directivas corresponde fundamentalmente a políticas armonizadoras, libre circulación de trabajadores, libertad de establecimiento o la libre prestación de servicios.

c) Las decisiones son disposiciones obligatorias, pero cuyo destinatario es concreto, normalmente un órgano comunitario. Se han utilizado junto con los reglamentos para la regulación y funcionamiento del Fondo Social Europeo y otros fondos estructurales.

Por lo que toca al tema de la jornada de trabajo, es de destacarse la Directiva 93/104/CEE, de 23 de noviembre de 1993, cuyos aspectos relevantes son:

I. Se aplicara:

a) A los períodos mínimos de descanso diario, de descanso semanal y de vacaciones anuales, así como a las pausas y a la duración máxima de trabajo semanal; $y$

b) A determinados aspectos del trabajo nocturno, del trabajo por turnos y del ritmo de trabajo.

Se señala, asimismo, que la Directiva se aplicará a todos los sectores de actividad, privados o públicos, en el sentido del artículo 2 de la Directiva 89/391/CEE, sin perjuicio del artículo 17 de la presente Directiva, con exclusión del transporte de carretera, aéreo, por ferrocarril, marítimo y de las actividades de los médicos en período de formación.

Por otra parte, se indica que las disposiciones de la directiva 89/391/ CEE se aplicarán plenamente a las materias a que se refiere el apartado 2 de

${ }^{20}$ Citado por García Ortega, Jesús y otros, op. cit. p. 153. 
la Directiva, sin perjuicio de las disposiciones más exigentes y/o específicas contenidas en la propia Directiva.

El artículo 2, expresa una serie de definiciones sobre el tiempo de trabajo, periodo de descanso, periodo de nocturno, trabajador nocturno, trabajo por turnos y trabajador por turnos.

El artículo 3, señala en materia de descanso diario, que los Estados miembros adoptarán las medidas necesarias para que todos los trabajadores disfruten de un periodo mínimo de descanso de once horas consecutivas en el curso de cada periodo de veinticuatro horas.

En materia de pausas, los Estados miembros adoptarán las medidas necesarias para que los trabajadores cuyo tiempo de trabajo diario sea superior a seis horas tengan derecho a disfrutar de una pausa de descanso cuyas modalidades y, en especial, la duración y las condiciones de concesión se determinarán mediante convenios colectivos o acuerdos entre interlocutores sociales o, en su defecto, mediante la legislación nacional.

Por cuanto al descanso semanal, se propone que por cada periodo de siete días, el trabajador descanse un periodo mínimo ininterrumpido de veinticuatro horas, a las que se añadirán once horas de descanso diario.

El artículo 6, que se refiere a la duración máxima del tiempo de trabajo semanal, expresa:

1) Se limite la duración semanal del tiempo de trabajo por medio de disposiciones legales, reglamentarias o administrativas o de convenios colectivos o acuerdos entre interlocutores sociales;

2) La duración media del trabajo no exceda de cuarenta y ocho horas, incluidos horas extraordinarias, por cada periodo de siete días.

Asimismo, se establece que los países miembros adoptarán las medidas necesarias respecto de vacaciones anuales, de por lo menos cuatro semanas; así como para la duración del trabajo moderno, con un máximo de ocho horas por cada periodo de veinticuatro.

En este contexto, el artículo 9, establece las medidas que se adoptarán para la evaluación de la salud y el traslado de los trabajadores nocturnos al trabajo diurno. 
Por lo que respecta al ritmo de trabajo, el artículo 13, señala que los Estados miembros adoptarán las medidas necesarias para que los empresarios que prevean organizar el trabajo con arreglo a cierto ritmo de trabajo tengan en cuenta el principio general de adecuación del trabajo a la persona, con objeto, en particular de atenuar el trabajo monótono y el trabajo acompasado, en función del tipo de actividad y de los requisitos en materia de seguridad y salud, especialmente en lo que se refiere a las pausas durante el tiempo de trabajo.

Sobre esta Directiva 93/104/CEE, adoptarán medidas para la evaluación de la salud y traslado de los trabajadores nocturnos al trabajo diurno.

Por lo que respecta al ritmo de trabajo, el artículo 13, señala que los Estados miembros adoptarán las medidas necesarias para que los empresarios que prevean organizar el trabajo con arreglo a cierto ritmo de trabajo, tengan en cuenta el principio general de adecuación del trabajo a la persona, con objeto, en particular de atenuar el trabajo monótono y el trabajo acompasado, en función del tipo de actividad y de los requisitos en materia de seguridad y salud, especialmente en lo que se refiere a las pausas durante el tiempo de trabajo.

Sobre esta Directiva 93/104/CEE, Montoya Melgar ${ }^{21}$ señala que ha sido incorporada en su totalidad al derecho positivo laboral español.

\section{LA CONSTITUCIÓN Y LA JORNADA DE TRABAJO}

\section{IV.1. Los Derechos Constitucionales Laborales}

La Constitución española es, además de norma en sí misma, norma de normas o fuente de las fuentes del derecho .En la misma, deben diferenciarse por tanto las normas que establecen como, cuando y en qué sentido, se deben dictar las restantes normas del ordenamiento.

El Tribunal Constitucional, en sentencia 80/1982, de 20 de diciembre, ${ }^{22}$ ha declarado que los preceptos constitucionales son origen inmediato de derechos y obligaciones, y no meros principios programáticos, al decir:

"Que la Constitución es precisamente eso, nuestra norma suprema y no una declaración programática o principal, es algo que se afirma de modo

\footnotetext{
${ }^{21}$ Montoya Melgar, Alfredo, op. cit. p. 343.

${ }^{22}$ Citada por Rodríguez - Zapata, Jorge, op. cit. p. 126
} 
inequívoco y general en su artículo 9.1 donde se dice que los ciudadanos y los poderes públicos están sujetos a la Constitución, sujeción o vinculatoriedad normativa que se predica en presente de indicativo, que tuvo lugar, según la disposición final, el mismo día de su publicación en el Boletín Oficial del Estado. Decisiones reiteradas de este Tribunal, en cuanto interprete supremo de la Constitución (art. 1 LOTC), han declarado ese indudable valor de la Constitución como norma".

Al tratar de los derechos fundamentales y libertades públicas, que tienen un "mayor valor" conforme a la Sentencia del Tribunal Constitucional 66/1985, de 23 de mayo, la vinculación de los poderes públicos a los mismos es mucho más intensa.

Asimismo, la Sentencia del Tribunal Constitucional 53/1985, de 11 de abril, declara que los derechos fundamentales son los componentes estructurales básicos tanto del conjunto del orden jurídico objetivo como de cada una de las ramas que lo integran, en razón de que son la expresión jurídica de un sistema de valores que, por decisión del constituyente, ha de informar el conjunto de la organización jurídica y política; son, en fin, como dice el artículo 10 de la Constitución "el fundamento del orden jurídico y de la paz social".

Los derechos fundamentales y libertades jurídicas, son la parte de la Constitución más propia y cercana al pueblo: Es la parte que el particular, ya sea ciudadano o extranjero, siente sobre si mismo; la que le protege y la que experimenta como suya, en cuanto le confiere posiciones jurídicas de ventaja en todos los ámbitos de la vida.

En la Constitución española, existe un núcleo de derechos y libertades de protección potenciada. Son las garantizadas en los artículos 14 a 29, así como la objeción de conciencia del artículo 30.

Sobre el contenido laboral de la Constitución española, suele clasificarse en tres grandes grupos: derechos fundamentales, derechos o libertades de los ciudadanos y principios económicos y sociales, tal clasificación se debe a la aplicabilidad o inaplicabilidad directa de los mismos y, fundamentalmente, a su distinto grado de protección o tutela.

Entre los derechos fundamentales (recogidos en los artículos 14 a 29 de la Constitución) solamente dos tienen un contenido específicamente laboral: el derecho a la libertad sindical y el derecho de huelga, ambos en el artículo 28; aunque también tiene carácter fundamental el derecho al traba- 
jo y a los beneficios de la seguridad social de los condenados a penas de prisión, conforme a la sentencia del tribunal constitucional 172/1989, de 19 de octubre y 17/19993, de 18 de enero. Pero otros derechos fundamentales tienen, asimismo, repercusiones importantes en la relaciones laborales: igualdad y no discriminación (artículo 14), libertad ideológica (artículo 16), intimidad personal (artículo 18), libertad de expresión (artículo 21), participación política (artículo 23), o el derecho a la tutela judicial (artículo 24).

Entre los derechos y libertades no fundamentales de los ciudadanos, se encuentran: el deber y el derecho al trabajo, a la libre elección de profesión $\mathrm{u}$ oficio, a una remuneración individual y familiar suficiente y a no discriminación por razón de sexo, así como la previsión de un estatuto de los trabajadores (artículo 35); también podríamos comprender el principio de libertad de empresa en el marco de una economía de mercado (artículo 38).

Por lo que toca a los principios económicos y sociales contemplados por el Capítulo III y los llamados "extrasistemáticos" (artículos 129 a 131).

De entre los primeros, ${ }^{23}$ cabe destacar la exigencia de que los poderes públicos promuevan, garanticen o mantengan determinadas actuaciones a favor de todos los ciudadanos en general o de determinados colectivos: principios de progreso social y económico, distribución de la renta, pleno empleo, estabilidad económica (artículo 40.1), formación profesional, seguridad e higiene en el trabajo, descanso, limitación de la jornada y vacaciones retribuidas (artículo 40.2), régimen público de Seguridad Social para todos los ciudadanos y libertad de regímenes complementarios (artículo 41), protección a los emigrantes (artículo 42), derecho a la salud (artículo 43), protección de la tercera edad (artículo 50) de los usuarios y consumidores (artículo 51).

Junto a estos principios, la Constitución española formula otros principios que, por hallarse fuera del capitulo II, suelen recibir el calificativo de principios "extrasistemáticos"; en este contexto, el artículo 121 se refiere a la participación de los interesados en la seguridad social y en la actividad de los organismos públicos cuya función afecte directamente a la calidad de vida o el bienestar general, así como a las distintas formas de participación en la empresa, desarrollo del cooperativismo y acceso de los trabajadores a la propiedad de los medios de producción.

El artículo 131, prevé la colaboración de los sindicatos y otras organizaciones, profesionales empresariales y económicas.

${ }^{23}$ García Ortega, Jesús y otros, op. cit. p. 41. 
Los derechos, libertades y principios constitucionales, en este caso de carácter laboral, deben ser regulados por la ley, la cual debe respetar el contenido esencial de las mismas, conforme al artículo 53.1 de la Constitución Española. Asimismo. El artículo 10.2 de la propia Constitución dispone que las normas de la propia Constitución relativas a los derechos, fundamentales o no, en ella reconocidos, se interpretarán conforme a la Declaración Universal de los Derechos Humanos y a los tratados y acuerdos sobre las respectivas materias, ratificadas por España.

En opinión de Palomeque López y Álvarez de la Rosa, ${ }^{24}$ la Constitución, culminando el proceso normativo iniciado durante la transición política, diseña ciertamente un modelo democrático de relaciones laborales, articulado sobre el reconocimiento de la libertad sindical como un derecho fundamental y el juego pleno de la autonomía colectiva que rompe decididamente con el sistema precedente, autoritario del Estado, efectivamente, al propio, tiempo que deroga de modo expreso las leyes fundamentales del Estado franquista, el Fuero del Trabajo entre ellas, y con él, la base de sustentación de todo el orden laboral anterior.

\section{III.3. LA LEY LABORAL}

En sentido amplio o material, la Ley es la norma jurídica que emana del Estado y comprende por ellos las diversas especies en que se concreta la producción normativa del mismo. Sin embargo, en un sentido más preciso, formal o técnico, el término Ley o Ley Formal, se reserva para designar únicamente la norma jurídica que emanan de los órganos del Estado, a las que constitucionalmente se atribuye de modo específico la potestad legislativa y posee la más alta jerarquía dentro del ordenamiento jurídico infraconstitucional. La Ley no deja de compartir ese rango normativo superior, si bien con normas procedentes del Poder Ejecutivo a las que el sistema atribuye, de modo excepcional y bajo determinados presupuestos habilitantes, valor legislativo.

La potestad legislativa del Estado radica constitucionalmente en las Cortes Generales. Asimismo, del sistema de producción de leyes, previsto en el capítulo II del título tercero de la Constitución Española, la tipología de los instrumentos legislativos propios o asimilados, puede ser:

a) Las leyes orgánicas (art. $81 \mathrm{CE}$ )

${ }^{24}$ Palomeque López, Manuel Carlos Álvarez de la Rosa, Manuel, op. cit. pp. 136-137. 
b) Las leyes ordinarias (arts. 87 a $91 \mathrm{CE})$

c) Los decretos - leyes (art. $86 \mathrm{CE}$ ).

En particular, el ordenamiento jurídico laboral español, cuenta con todos estos instrumentos legislativos, que pasan a formar parte de su elenco instrumental, tan pronto como tiene por objeto la regulación de las relaciones de trabajo y de los restantes contenidos que integran el dominio institucional del derecho del trabajo.

En este escenario, dentro de las leyes orgánicas laborales, tenemos a la LO 11/1985, de 2 de agosto, de libertad sindical, que desarrolla legislativamente el artículo 28.1 de la Constitución Española.

En el terreno de leyes ordinarias, de contenido laboral, tenemos la L8/ 1980, de 10 de marzo, por la que es aprobado el Estatuto de los trabajadores (hoy texto refundido aprobado por RD Legislativo 1/1995, LET); 1.51/1980, de 8 de octubre, básica de empleo; la L14/1994, de 1 de julio, por la que se regulan las empresas de trabajo temporal; la L31/1995, de 8 de noviembre de prevención de riesgos laborales; la L42/1997, de 14 de noviembre, ordenadora de la Inspección del Trabajo y Seguridad Social; L 39/ 1999, de 5 de noviembre, para promover la conciliación de la vida familiar y laboral de las personas trabajadoras.

Por cuanto a Decretos Legislativos, en materia laboral, tenemos el RD Legislativo 521/1990, de 27 de abril, por el que se aprueba el texto articulado de la Ley de Procedimiento Laboral (hoy texto refundido); RD Legislativo 1/1994 de 20 de junio, por que se aprueba el texto refundido de la Ley General de la Seguridad Social; RD Legislativo 1/1995, de 24 de marzo, por el que se aprueba el texto refundido de la Ley de los Trabajadores; RD Legislativo 2/1995, de 7 de abril, por elque se aprueba el texto refundido de la Ley de Procedimiento Laboral; RD Legislativo 5/2000, de 4 de agosto, por el que se aprueba el texto refundido de la Ley sobre infracciones y sanciones en el orden social.

En el ámbito de los Decretos - Ley, que son pocos por el reducido espacio que les deja la Constitución, en materia laboral, encontramos, el RD L 8/1997, de 16 de mayo, de medidas urgentes de reforma del mercado de trabajo y fomento de la contratación indefinida (convertido en Ley ordinaria L 63/1997); RD - L 5/2001, de 2 de marzo, de medidas urgentes de reforma del mercado de trabajo para el incremento del empleo y la mejora de su calidad (convertido en la ley ordinaria L 12/2001, de 9 de julio); RD L 16/ 
2001, de 27 de diciembre, de medidas para el establecimiento de un sistema de jubilación gradual y flexible; RD - L 5/2002, de 24 de mayo, de medidas urgentes para la reforma del sistema de protección por desempeño y mejora de la ocupabilidad.

En particular, la Constitución Española en el artículo 35.2, señala que "La Ley regulará un estatuto de los trabajadores".

Aún cuando Palomeque López y Álvarez de la Rosa ${ }^{25}$ opinan que la expresión "estatuto de los trabajadores", es una expresión ajena a la tradición jurídica laboral española, por cuanto que su uso cotidiano es más propio del Derecho Administrativo, sin duda, la influencia jurídica italiana tuvo en España un buen recipiendario, al que la Constitución le otorgó una consideración especial.

\section{LA JORNADA DE TRABAJO}

\section{V.1. Fuentes de Regulación}

La regulación de la jornada de trabajo se configura en torno a tres fuentes: la intervención normativa del Estado, los convenios colectivos y la voluntad de las partes.

Las normas estatales históricamente se han constituido en las normas de derecho necesario, cuyo contenido mínimo no puede empeorare, sino que debe cumplirse o, en su caso, ser objeto de mejora.

En materia de jornada de trabajo, las fuentes reguladoras han pretendido históricamente, lograr su disminución y, en la actualidad, su mejor distribución, que se traduce en dos vertientes; una, la de regular el poder de dirección del empresario, en cuanto a fijar el tiempo de trabajo necesario podrá llevar adelante el proceso de producción y la otra, atender necesidades vitales del trabajador como persona y como parte de un entorno familiar y social.

Sin duda, los intereses del empleador y del trabajador, tensionan la relación laboral, lo que ha provocado que la Constitución Española, señale que los poderes públicos fomentarán una política que garantice "el descanso necesario, mediante la limitación de la jornada de trabajo".

${ }^{25}$ Palomeque López, Manuel Carlos y Álvarez de la Rosa, Manuel, op. cit. p. 191. 
En el caso del Estatuto para los Trabajadores, la expresión del Estado tiene por objetivo la fijación de mínimos, a través de una regulación coherente del tiempo de trabajo, como la especifican los artículos 12, 23 y 34 a 38, que se constituyen en el marco de referencia para las convenciones, colectivas e individuales, tan es así, que la STC 210/1990, ha dejado establecido que "en lo que atañe a la jornada de trabajo, la preeminencia de la Ley, por lo que hace a la fijación de los límites de la misma, ha sido expresamente consagrada en el artículo $40.2 \mathrm{CE}$, de manera que los convenios colectivos, y no sólo los contratos de trabajo, han de respetar ineludiblemente el límite legal, en las condiciones establecidas por la propia Ley". En complemento, la Ley sobre Infracciones y Sanciones del Orden Social, señala en el artículo 7.5 , que se considera como infracción grave, la transgresión de las normas y límites legales o pactados, en materia de jornada.

Sin embargo, como se ha expresado, los convenios colectivos y los contratos individuales pueden mejorar los límites mínimos establecidos por la norma estatal; de tal manera, que la suplementariedad entre Ley, convenio y contrato de trabajo, ha de traducirse el mínimo legal, pero nunca pueden empeorarlo, por que este es el sentido del artículo 34.1 del Estatuto de los trabajadores, cuando señala que "la duración de la jornada de trabajo será la pactada en los convenios colectivos o contrato de trabajo".

La trascendencia de los convenios colectivos y los contratos de trabajo, estriba en cuanto que unifica criterios y sistemas para el control del tiempo efectivo de trabajo. Por tanto, la ley estatal establece, en el caso de jornada, el máximo legal, pero la negociación colectiva será la encargada de fijar la distribución de la jornada.

\section{V.2. Trabajo Efectivo}

Si partimos del concepto de que la jornada ordinaria de trabajo, se entiende como el tiempo que cada día, semana o año dedica el trabajador a la ejecución de su prestación del trabajo, sin duda estamos arribando al contexto de jornada efectiva.

Esta cuestión se desprende de lo dispuesto por el artículo 34.5 del Estatuto de los trabajadores que indica que "tanto al comienzo como al final de la jornada diaria", el trabajador debe" encontrarse en su puesto de trabajo", cumpliendo los menesteres del mismo. Al respecto, se han establecido criterios judiciales en el sentido de que no se computa como jornada, el tiempo de cambio de ropa SCT 26 de febrero 1982; ni el invertido en fichar SCT 31 de marzo 1982, ni el del bocadillo, si no hay pacto expreso. Asimis- 
mo, algunos lapsos no cuentan para el cómputo de jornada, los tiempos de desplazamiento en la ida y vuelta del trabajo, los desplazamientos desde la entrada en el centro de trabajo hasta el puesto, entre otros.

Sin embargo, es jurídicamente posible que la negociación colectiva introduzca regulación sobre el tiempo efectivo y actividades concretas, para el cómputo de la jornada.

\section{V.3. La Jornada ORdinaria}

Los artículos 34 a 38 del Estatuto de los Trabajadores, regulan la jornada máxima legal y su distribución, que tienen un desarrollo reglamentario en el Real Decreto 1561/1995, de 21 de septiembre, sobre jornadas especiales de trabajo. Estas normas legales y reglamentarias, tiene en cuenta las prescripciones de la Directiva 93/104, de 23 de noviembre de 1993, relativa a determinados aspectos de la ordenación y limitación del tiempo de trabajo.

Conforme a García Ortega ${ }^{26}$ la jornada tiene las siguientes limitaciones:

1) La duración máxima de la jornada ordinaria de trabajo será de 40 horas semanales de trabajo de promedio en cómputo anual. En este sentido, la jurisprudencia ha concretado que la jornada máxima anual equivale a 1826 horas y 27 minutos de trabajo (resultado de multiplicar 40 horas por las semanas del año y restando las vacaciones, descanso semanal y días festivos). Se trata de un límite máximo de derecho necesario, que no impide que en los convenios o en los contratos individuales pueda establecerse una jornada inferior.

Aunque se fije el límite como promedio, la distribución anual e irregular de la jornada, sólo puede hacerse mediante convenio colectivo o acuerdo de empresa.

2) A efectos del computo de las 40 horas semanales se tiene en cuenta exclusivamente el trabajo efectivo. En tal sentido, el artículo 34.5 del Estatuto de los trabajadores, como lo hemos señalado, previene que el tiempo de trabajo se computará de modo que, tanto al comienzo como al final de la jornada diaria, el trabajador se encuentre en su puesto de trabajo.

En todo caso, respecto al cómputo de jornada, en cada caso concreto habrán de tenerse en cuenta las posibles condiciones más beneficiosas y lo que establezcan las normas sectoriales (convencionales o reglamentarias).

${ }^{26}$ García Ortega, Jesús, op. cit. p. 344. 
3) La jornada máxima anual, tanto la legal como la convencional, puede ser objeto de una distribución irregular a lo largo del año, mediante convenio colectivo o por acuerdo entre la empresa y los representantes de los trabajadores, tal como lo dispone el artículo 34.2 del Estatuto de los trabajadores. Es decir, el límite de 40 horas de trabajo a la semana es disponible. Así durante una semana puede trabajarse más de cuarenta horas sin que estas tengan la consideración de extraordinarias. De la misma manera, puede pactarse el descanso en días que legalmente no sean festivos.

En todo caso, la distribución irregular de la jornada esta sometida a tres limitaciones: a) la jornada diaria de trabajo no podrá ser superior a nueve horas, si bien se trata de una limitación que puede modificarse por convenio colectivo o, en su defecto, por acuerdo con las representantes de los trabajadores. b) Debe respetarse de forma imperativa el descanso mínimo de doce horas entre el final de una jornada y el comienzo de la siguiente. c) Asimismo, debe respetarse el descanso de día y medio semanal. Aunque se puede, reglamentariamente, ampliar o reducir tanto el descanso diario como el semanal.

Como lo señala Palomeque López y Álvarez de la Rosa, ${ }^{27}$ la jornada así establecida de 40 horas semanales, tiene la característica de ser considerada como máxima ordinaria. Quien trabaja, más horas para un empresario lo hará con carácter extraordinario y así deberá ser remunerado, trabajar menos horas, tiene a su vez, una doble posibilidad de tratamiento jurídico; la menor jornada es producto de un pacto, individual o colectivo; por tanto, ordinaria para el trabajador, empresa o sector a que se refiera el pacto, o bien el modelo aplicable es el máximo legal, por lo que trabajar menos significa, sencillamente, percibir menos salario.

La duración de la jornada ha pasado de tener como parámetro la del día, a la de la semana. Este traslado tiene una obvia razón justificativa;:la mejor distribución del tiempo de trabajo. Carecería de sentido pasar del modelo diario al semanal, si se trabajase a la semana seis días: la jornada diaria y la semanal darían como consecuencia el mismo margen de maniobra. Sin embargo, aumentando el descanso semanal, el conjunto de la jornada de cada semana, permite un reparto de acuerdo a las necesidades de las partes en el trabajo diario. Esa mayor posibilidad de combinaciones para una mejor distribución del tiempo de trabajo, encuentra en la jornada anual su mejor campo de aplicación.

En relación a la jornada ordinaria, es menester señalar que tratándose de trabajadores menores de dieciocho años no podrán realizar más de ocho

${ }^{27}$ Palomeque López y Álvarez de la Rosa, op.cit. p.864. 
horas diarias de trabajo efectivo, incluyendo, en su caso, el tiempo dedicado a la formación. Incluso, como lo indica el artículo 34.3 del Estatuto de los Trabajadores, esas ocho horas diarias será el máximo posible, aunque el menor trabaje para más de un empresario. El menor trabajador, por otra parte, es sujeto de la aplicación de las normas del Real Decreto 156/1995, sobre regímenes de descanso alternativos, ampliaciones de jornada y trabajo a turnos.

El Estatuto de los trabajadores autoriza al Gobierno, a propuesta del Ministerio del Trabajo y previa consulta a las Organizaciones Sindicales y Asociaciones Empresariales, a establecer ampliaciones o limitaciones en la ordenación y duración de la jornada de trabajo y de los descansos para aquellos sectores y trabajos por sus peculiaridades así lo requieren, según lo disponen los artículos 34.7 y 36.1 cuarto párrafo, que han sido desarrollados en el Real Decreto 1561/1995, de 21 de septiembre, modificado por el Real Decreto 285/2002.

En este sentido, el Real Decreto precisa los supuestos de ampliaciones, limitaciones y deducciones de la jornada de trabajo, de la siguiente manera:

\section{a) Ampliaciones}

1. Empleados de fincas urbanas con plena dedicación.

2. Guardias y vigilantes no ferroviarios.

3. Transportes y trabajo en el mar.

4. Trabajo de puesta en marcha y cierre de los demás.

5. Trabajo en condiciones especiales de aislamiento y lejanía.

6. Trabajos con jornada fraccionada.

\section{b) Limitaciones de Jornada}

1. Trabajos expuestos a riesgos ambientales.

2. Trabajos en el campo.

3. Trabajos en el interior de las minas. 
4. Trabajos de construcción y obras públicas.

5. Trabajo en cámaras frigoríficas y de congelación.

\section{c) Reducciones de Jornada}

1. Para que e trabajador pueda atender o proveer ciertas atenciones familiares.

2. La inferior al trabajo habitual.

3. Para recibir formación en materia de prevención de riesgos laborales.

Por lo que respecta a estas jornadas especiales, es obvio que se introducen reglas distintas a las de la jornada ordinaria. Así en el caso de ampliación de la jornada, puede decirse que una parte, no todo el tiempo de trabajo, ha de computarse como jornada y, por la otra, el trabajo puede prestarse durante un tiempo que exceda de las cuarenta horas semanales, diferenciándose de esa manera, trabajo efectivo y trabajo de presencia. En los casos de limitación de la jornada, el propósito es la tutela de la integridad física del trabajador, frente a trabaos de riesgo. En el supuesto de reducción de jornada, se atiende a circunstancias personales del trabajador o a la educación para reducir o prevenir riesgos laborales.

\section{V.5. Horario de Trabajo}

Como lo expresan Palomeque López y Álvarez de la ${\operatorname{Ros} a,{ }^{28}}^{28}$ la fijación de la jornada de trabajo se remite a modelos, legales o pactados, de naturaleza semanal o anual. La duración de tales modelos temporales puede, a su vez, sufrir variaciones a lo largo del año. Sin embargo, la citada duración, incluso su distribución en el año, precisa ser más concreta y referirla a cada día en que se trabaja. Por tanto, el horario de trabajo no es otra cosa, que la distribución de la jornada.

La certeza en el horario de trabajo es de suma importancia, por cuanto asume la realidad fisiológica de limitar el esfuerzo laboral del trabajador y el interés empresarial de organizar el sistema productivo. En consecuencia, el horario de trabajo otorga certeza y seguridad al trabajo ordinario de cada día.

${ }^{28}$ Palomeque López y Álvarez de la Rosa, op. cit. p.871. 
La fijación del horario de trabajo es competencia inicial del empresario y le nace de su facultad de organizar el trabajo.

En este tenor, el horario de trabajo es la determinación de los momentos precisos, como lo apunta Alonso Olea y Casas Baamonde, ${ }^{29}$ en que cada día se ha de entrar y salir del trabajo según la jornada, y sitúa, por tanto, con exactitud cuando, dentro de cada día, la prestación es debida. Los momentos pueden ser los mismos todos los días del año o variar según el calendario.

Sin embargo, esta competencia inicial del empresario para fijar el horario de trabajo, no impide que se manifieste como condición sustancial del trabajo, como producto de un pacto individual o convenio colectivo, tal como se infiere del artículo 41.1, b del Estatuto de los trabajadores. En este caso, el horario se torna en indisponible unilateralmente para el patrón.

Sea por decisión unilateral del empresario o consecuencia de pactos individuales o convenios colectivos, el horario de trabajo delinea perfectamente la prestación de trabajo, dentro de un espacio temporal predeterminado e invariable aunque sea irregular.

Puede fijarse, en opinión de Palomeque López y Álvarez de la Rosa, ${ }^{30}$ incuso un horario flexible. Lo flexible hace referencia a la posibilidad de elección de horario para cumplimentar el trabajo diario exigido, se refiere a jornada ordinaria y nada tiene que ver con el trabajo a tiempo parcial, la elección es individualizada; esto es, cada trabajador, dentro de unos márgenes indisponibles y previamente establecidos, elige el horario de trabajo. El horario flexible será objeto de pacto entre empresa y trabajador y éste, será el regulador de tal horario flexible.

El horario de trabajo puede desarrollarse prestando el trabajo en forma continua o en régimen de horario partido. Diferenciándose el uno del otro, en que el periodo de descanso se sitúa entre los dos tiempos del horario o dentro del espacio continuado del trabajo. El Estatuto de los Trabajadores, en el artículo 34.4 sólo regula la pausa en la jornada continuada, siempre que su duración exceda de seis horas diarias, en cuyo caso, la pausa no puede ser menor a quince minutos.

En la pausa o descanso interjornada, la regla general indica que este tiempo no cuenta para el computo de la jornada de trabajo; pero al mismo

${ }^{29}$ Alonso Olea, Manuel y Casas Baamonde, Ma. Emilia, op. cit. p. 273.

${ }^{30}$ Palomeque lópez, Manuel Carlos y Álvarez dela Rosa, Manuel, op. cit. p. 872. 
tiempo, el propio artículo 34.4 permite que el convenio colectivo o el contrato de trabajo lo consideren como tiempo de trabajo efectivo, por tanto remunerado.

En el caso de trabajadores menores de dieciocho años, el periodo de pausa o descanso, cuando la jornada exceda de cuatro horas y media, tendrá una duración mínima de treinta minutos.

Vinculando con el horario de trabajo, esta el calendario laboral, que como lo dispone el artículo 34.6 del Estatuto de los trabajadores, se elaborará anualmente por la empresa. Se trata de un documento en el que deben figurar los días de trabajo durante el año, días de descanso, fiestas y otras jornadas en las que no se trabaja y también el número de horas de trabajo ordinario que corresponde a cada una de las jornadas laborales; el calendario debe exponerse en un lugar visible de cada centro de trabajo. Respecto del calendario laboral, el Real Decreto 1561/1995, de 21 de septiembre, en la $3^{\text {a }}$ disposición adicional señala que sin perjuicio de las competencias reconocidas a las representantes de los trabajadores en materia de jornada, éstos tendrán derecho a ser consultados por el empresario.

\section{LA JORNADA DE TRABAJO EN EL CONTEXTO DE LA FLEXIBILIZACIÓN Y DE LA DESREGULACIÓN}

\section{VI.I. El CONTEXTo}

En torno al derecho del trabajo, la flexibilización y la desregulación, constituyen el frente a través del cual se fincan las transformaciones de esta rama del derecho.

En opinión de Palomeque López y Álvarez de la Rosa, ${ }^{31}$ el ordenamiento laboral de las sociedades desarrolladas se ha visto afectado desde hace décadas por un nuevo ámbito económico, producto de una aceleración de los procesos históricos en juego, desconocido por su intensidad en los sistemas de relaciones industriales. El nuevo escenario institucional no deja de ofrecer, así pues, un panorama complejo de profundas transformaciones en las relaciones de producción, sobre la que descansa el sistema normativo laboral, cuyas expresiones, según los propios autores, son:

1. Los cambios intensos advertidos en el propio proceso de producción de bienes y servicios (el cambio tecnológico, la informatización y la robotización, las nuevas tecnologías), que han ampliado el tipo de pres-

${ }^{31}$ Palomeque López, Manuel Carlos y Álvarez de la Rosa, Manuel, op. cit., p. 105. 
tación de trabajo requerido por las empresas, frente al modelo tradicional dominante del trabajo industrial.

2. Los cambios experimentados por la actividad económica, como la globalización o mundialización de la economía y consiguiente pérdida del valor de los modelos puramente nacionales de producción e instauración de nuevas formas de competitividad internacional entre las empresas a partir de la cualificación personal de la mano de obra y del costo económico de la misma. De este modo, lo que caracteriza el nuevo escenario es el llamado efecto "aritmético" de la globalización económica, ya que, de una parte, las instituciones políticas, en tanto que de otra, las empresas transnacionales lo hacen a escala mundial debido a la disminución continua de los costos de producción.

3. Los cambios producidos en la estrategia empresarial encaminada a conseguir una mayor eficiencia en la organización del trabajo, como los procesos de concentración económica de empresas o de descentralización productiva, como estrategia de gestión productiva, en el desplazamiento hacia otras empresas de funciones o actividades del ciclo productivo que previamente se realizaban en la misma, como lo externalización, subcontratación, outsourcing, entre otras.

4. Los cambios producidos en la estructura y composición, así como derivadamente en el comportamiento y actitud de la clase trabajadora, en cuyos ámbitos se muestran fenómenos nuevos, como el acceso creciente de la mano de obra femenina y joven a los mercados de trabajo, difuminación de la conciencia social, crisis de solidaridad entre trabajadores, entre otros.

5. Los cambios producidos también en el comportamiento de las organizaciones sindicales. De un sindicalismo de masas dedicado a la contestación de los fundamentos de la sociedad capitalista, se ha pasado a un sindicalismo más implicado en el funcionamiento del aparato institucional del Estado.

La globalización y su incidencia en el derecho del trabajo, ha devenido en la necesidad de adaptación del ordenamiento laboral a la evolución de las diversas formas de organización del trabajo en la sociedad contemporánea, de modo que puede seguir realizando la función de cohesión social que le es propia, más allá del reducto industrial tradicional, ha justificado ciertamente, una amplia serie de propuestas de modificación al derecho laboral. 
La estrategia de transformación o modificación del derecho laboral, en opinión de Montes de $\mathrm{Oca}^{32}$ comprende, fundamentalmente: jornada, retribución, lugar de trabajo y contrataciones.

Por otra parte, Dávalos, ${ }^{33}$ sostiene que la globalización atenta contra los trabajadores, por cuanto que las tendencias sobre el pago por horas, movilidad del trabajador y, en general la filosofía empresarial de la flexibilidad del derecho del trabajo no busca enmendar la deficiencia que tenga la legislación del trabajo; los patrones, señala intentan desmantelar las instituciones fundamentales, borrar los derechos de la clase trabajadora, que son y representan la historia del derecho laboral.

Martín Valverde, ${ }^{34}$ considera que las transformaciones económicas inéditas hasta hoy, han repercutido en el derecho del trabajo, originado instituciones y principios de regulación que no existían antes, desarrollando otros que se encontraban en fase embrionaria y obligando, en fin, a reformar parcelas enteras en este sector del ordenamiento. En esta línea de evolución se hallan las normas de fomento del empleo y de reparto de trabajo; las encaminadas a la flexibilización del mercado laboral, en especial, las relativas a las modalidades de contratación laboral; y la implantación o reformas de las instituciones de garantía de rentas laborales y sociales, la adaptación a las transformaciones del sistema productivo se han de sentir además, en múltiples disposiciones sobre el empleo.

Sin embargo, es de reconocerse que la doctrina del actual derecho del trabajo, orienta sus tendencias hacia la búsqueda de nuevas formulas normativas del derecho laboral que atiendan el impacto y el efecto de globalización en las relaciones obreros patronales, al respecto Cellis, ${ }^{35}$ sostiene que el proceso globalizador requiere de la conformación de un orden legal que lo regule, con criterio de unidad en aras de consolidación del bienestar de los pueblos, trabajando estrategias éticas como basamento de un espacio equitativo en donde la igualdad de oportunidades sea un hecho cierto y sustentable.

Como se desprenden de lo expuesto, la globalización es una realidad social y económica, a la que el derecho no puede ignorar, si es que pretende

\footnotetext{
${ }^{32}$ Montes de Oca, Santiago, "La Flexibilidad en la Relación de Trabajo", Boletín Mexicano de Derecho Comparado, Instituto de Investigaciones Jurídicas UNAM, México, 1991, p. 18.

${ }^{33}$ Dávalos, José, Tópicos Laborales, Editorial Porrúa, México, 2000, p. 677.

${ }^{34}$ Martín Valverde, Antonio y otros, op. cit. p. 85.

${ }^{35}$ Cellis Chaguin, Wilma, "La globalización laboral y la seguridad social", Instituto de Derecho Comparado, anuario, Universidad de Carobobo, Venezuela, 2000, p. 725.
} 
continuar en su papel de regulador, de orden y de estabilidad social; la globalización impacta al sistema jurídico en general, como se ha apuntado; sin embargo, el derecho del trabajo es particularmente sensible, por la propia materia que regula, en donde las personas que prestan trabajo por cuenta ajena y los empleadores o patrones, requieren de reglas positivas eficaces, y en congruencia con el contexto y las circunstancias propias de un mundo en permanente interrelación.

Los profesores Palomeque López y Álvarez de la Rosa, ${ }^{36}$ indican que hay ámbitos preferentes para la reflexión y la crítica, sobre la adaptación del derecho del trabajo, como:

1. La delimitación institucional del derecho del trabajo. Toda vez que en el proceso de adaptación se plantea la pregunta sobre la configuración de la propia disciplina jurídica, en virtud de que las nuevas situaciones económicas y sociales, provocan una huida de ciertas cuestiones, tradicionalmente reguladas por el derecho laboral, hacia otras disciplinas jurídicas, particularmente por las nuevas formas de organización de la producción de trabajo.

2. El sistema normativo laboral. Considerando que el propio sistema normativo de las relaciones de trabajo no ha escapado a la reflexión de adecuación, principalmente a través de la desregulación, autonomización y la función uniformadora de la negociación colectiva.

3. El contenido del ordenamiento laboral. Estimando que el derecho del trabajo está sometido a factores económicos que apuntan, como se ha dicho, a la adaptación de las normas laborales. En este sentido las tendencias de desregulación y flexibilización parecen apuntar hacia nuevos enfoques: los poderes del empresario, modalidades en la contratación, movilidad laboral, prestación laboral, entre otros, que sin duda, son un plus a la citada desregulación y flexibilización, toda vez que se introducen modalidades trascendentes al contenido de las normas laborales.

4. Las actitudes de los sujetos de las relaciones de trabajo. Sin duda, el proceso de adaptación del derecho del trabajo, tiene un reflejo obligado y necesario en la actitud de los patrones o empleadores y trabajadores, quienes adquieren nuevas responsabilidades en la negociación colectiva, a efecto de que la desregulación y la flexibilización cumplan su finalidad.

${ }^{36}$ Palomeque Álvarez, Manuel Carlos y Álvarez de la Rosa, Manuel, op. cit. p. 107 y 108. 
Por la materia de este trabajo, nos centraremos en el comentario de la desregulación y de la flexibilización como tendencias que orientan la adaptación del derecho del trabajo, y que mayormente inciden en las condiciones de trabajo, como la jornada; pero sin dejar de reconocer la importancia de otras cuestiones que están presentes en el debate sobre la adaptación o transformación del derecho laboral.

Pérez Amorós, ${ }^{37}$ define la flexibilidad como un proceso que consiste en convertir la fuerza de trabajo, adquirida por el empresario en el mercado contratando a un trabajador, en trabajo efectivo, cuyos resultados se incorporan automáticamente al haz de propiedades del referido empresario. Flexibilización es facilitar la extracción del trabajo efectivo y facilitar su utilización. Es en suma una relación social por naturaleza conflictiva, al amparo social por naturaleza conflictiva, al amparo de la cual se intenta modificar el instrumento que regula el derecho del trabajo.

Para Palomeque López y Álvarez de la Rosa, ${ }^{38}$ la flexibilización supone mecanismos de adaptabilidad normativa en las distintas fases de la relación laboral, destinados a aumentar los poderes del empresario en la dirección y control de la mano de obra, la oferta de modalidades de contratación, del contenido de la propia relación de trabajo, retribución, movilidad funcional, jornada de trabajo y ampliación de los supuestos de extinción del contrato de trabajo.

Por su parte Pedrazzolli, ${ }^{39}$ considera la flexibilización como la protección normativa, por medio de la cual se pretende evitar intolerables explotaciones y la competencia a la baja entre trabajadores, en sectores de fuerza de trabajo débiles, con la finalidad de combatir el desempleo, así como para regular la externalización de funciones de la empresa cuando se presenta el decaimiento de la salidas tradicionales de la profesionalidad de las nuevas generaciones escolarizadas, que la hegemonía del sector industrial ha estratificado y empobrecido.

El maestro Montes de $\mathrm{Oca}^{40}$ señala que la flexibilidad es el elemento complementario de la relación de trabajo conforme al cual los trabajadores

\footnotetext{
${ }^{37}$ Pérez Amorós, F., "El Circuito de la Flexibilidad", Revista de la Facultad de Derecho, de la Universidad Competente, Madrid, España, no. 14, 1988, p. 85 y ss.

${ }^{38}$ Palomeque López , Manuel Carlos y Álvarez de la Rosa, Manuel, op. cit. p. 114.

${ }^{39}$ Pedrazzolli, Marcel, "El trabajo que cambia; problemas de calificación y método", Revista de la Facultad de Derecho, de la Universidad Completense, Madrid, España, Nezo 1987, p. 173 y ss.

${ }^{40}$ Barajas Montes de Oca, Santiago, op. cit. p. 17.
} 
y patrones aceptan un ajuste económico, con carácter provisional o temporal, a las condiciones de trabajo establecidos, de una empresa en crisis.

En cuanto a la desregulación, Palomeque López y Álvarez de la Rosa ${ }^{41}$ expresan que ésta se traduce en la desaparición de la regulación imperativa (de derecho positivo o convenida colectivamente) y cuya consecuencia de este "vacío normativo", será el protagonismo de la negociación colectiva para ocuparlo y de la autonomía privada, tratándose de contratos individuales. Es decir, estaríamos en una perspectiva de reducción normativa del derecho del trabajo, para que sean los patrones y los trabajadores, quienes mediante acuerdos colmen los vacíos normativos, en atención a los intereses y requerimientos propios de cada relación de trabajo, empresa o sector.

En resumen, podríamos señalar que la desregulación es; esencialmente una retirada, huida o suspensión de la norma positiva laboral, con el objeto de que patrones o empleadores y trabajadores, si así lo estiman, acuerden la forma y manera de llenar ese vacío normativo, en atención a sus intereses, necesidades y circunstancias.

La flexibilización, por su parte, ya sea que se aborde en su esencia misma, como en el caso de Palomeque López y Álvarez de la Rosa, o en atención a sus consecuencias o materialización como lo hacen los profesores Pérez Amorós, Pedrazzolli y Montes de Oca, es materialmente darle a la norma positiva una laxitud o amplitud tal, que permita a patrones y trabajadores, mediante acuerdos, adapten la norma a sus particulares intereses y necesidades.

Sobre el tema, la Organización Internacional del Trabajo, en la 72a , Reunión de la Conferencia en Ginebra, en el año de $1986,{ }^{42}$ se pronuncio sobre los efectos de los problemas económicos derivados de la globalización.

Las recomendaciones de la Organización Internacional del Trabajo, son: 1) Recuperar los gastos y la demanda interna, no para evitar la recesión, pero si para reducir su duración. 2) Frente al fenómeno inflacionario, impedir la reacción natural de los sindicatos, para evitar el incremento de mano de obra y costos de producción. 3) Poner en ejecución programas que impliquen ciertas ventajas salariales y de seguridad social, así como explorar esquemas de flexibilización normativa, para favorecer la negociación colectiva.

\footnotetext{
${ }^{41}$ Palomeque Álvarez, Manuel Carlos y Álvarez de la Rosa, Manuel, op. cit. p. 114.

${ }^{42}$ OIT, Actos Provisionales, $72^{\mathrm{a}}$ Asamblea Ginebra, 1986, p. 115 y ss.
} 
La aparición de la desregulación y la flexibilización, sin duda, han traído una distinta política legislativa laboral, aceptada por algunos países y rechazada por otros. Para algunos, la flexibilización es un experimento carente de legitimación y que lesiona los principios fundamentales y tradicionales del derecho laboral, para otros, tal vez la mayoría, es un proceso material del derecho del trabajo, frente a las nuevas circunstancias sociales y económicas.

Lo cierto es que la desregulación y la flexibilización se van imponiendo gradual y crecientemente en los países desarrollados, principalmente en la unión europea.

La política legislativa, centrada en las condiciones de trabajo, han tenido como punto de partida, a la jornada de trabajo. Sin duda, las prácticas de desregulación y flexibilización varían de país a país, sin embargo, es posible detectar las líneas generales que orientan la política legislativa en materia de jornada de trabajo.

El contrato de trabajo, ya sea individual o colectivo, tienen en la jornada de trabajo o tiempo laboral, una de sus expresiones esenciales, por cuanto definir el discurrir del cumplimiento de la obligación de trabajar. Es decir, el tiempo o periodo durante el cual el trabajador esta obligado a poner su actividad laboral a disposición del patrón o empleador.

La lucha histórica sobre la jornada de trabajo esta inscrita en los orígenes y desenvolvimiento del derecho del trabajo y, evidentemente, del desarrollo del movimiento obrero, como necesidad para proteger al trabajador física y moralmente. Cuestión que fue resuelta por el Estado, con la colaboración innegable de la negociación colectiva.

En la actualidad, las líneas legislativas sobre la jornada del trabajo está oscilando de la disminución de las horas de trabajo, hacia la distribución del tiempo laboral, a partir de un horario flexible y la redistribución de la jornada en diversas épocas del año, incluso de los descansos y vacaciones, como se ha visto en el modelo español.

Esta pretensión sobre distribución de la jornada del trabajo, como tendencia legislativa actual, se configura en torno de tres fuentes: las normas jurídicas, los convenios o contratos colectivos y la voluntad de las partes. Estas tres fuentes, tienen obviamente un peso específico distinto, que hoy en día parece favorecer a la negociación colectivo y a la voluntad, por la similar tendencia desregulación o retiro de la norma laboral. 


\section{PROPUESTAS Y CONCLUSIONES}

\section{VIII.I. Propuestas}

La desregulación y la flexibilización plantean retos interesantes para el derecho del trabajo, como el cuidado que debe tenerse en la legislación, a efecto que la negociación colectiva o los pactos individuales, no constituyan riesgos para los derechos y libertades públicos, que constitucional y legalmente se le reconocen al trabajador en esa condición concreta y como persona humana y su extensión a la familia y entorno social.

En el caso de la jornada de trabajo, una excesiva flexibilización puede incidir negativamente en el tiempo libre o de ocio, en los días de descanso y vacaciones, que se traducen materialmente en una invasión a derecho y libertades del trabajador, por cuanto que algunos aspectos de su vida familiar y social, se condicionan a decisiones patronales.

Por otra parte, es de reconocerse que la globalización exige que el derecho del trabajo se involucre en un proceso de adaptación y así, dar respuesta a intereses diversos a los tradicionales

Asimismo, la desregulación y la flexibilización obligan a trabajadores y patrones a entender las razones de la adaptación, sin que ello desplace totalmente el carácter tuitivo del derecho laboral y el respeto a los derechos y libertades públicos.

\section{CONCLUSIONES}

PRIMERA. En España, se confirma que el derecho del trabajo ha convivido siempre, con los requerimientos de la economía, cuyas relaciones disciplinarias han formado parte, en todo momento y por derecho propio, de la relación de las grandes cuestiones teóricas de esta disciplina: adaptación y flexibilidad.

SEGUNDA. El nuevo escenario que plantea la Unión Europea, no deja de ofrecer un panorama complejo de profundas transformaciones en las relaciones de producción, sobre el que descansa el sistema normativo laboral.

TERCERA. Los cambios en los procesos de producción y en la estrategia empresarial, encaminada a conseguir una mayor eficiencia en la organización del trabajo, como los procesos de concentración económica de empre- 
sas, de fusión e integración de sociedades, para hacer frente a exigencias de competitividad internacional, son una presión para la adaptación de las normas laborales.

CUARTA. Los cambios de los procesos de producción también inciden en el comportamiento de las organizaciones sindicales. De un sindicalismo de masas dedicado a la contestación de los fundamentos de la sociedad capitalista, se ha pasado a un sindicalismo de cada vez más implicado en el funcionamiento del aparato institucional del Estado y en los intereses económicos de las empresas.

QUINTA. En España la necesidad de adaptación, se ve expresada en la desregulación y en la flexibilización de las normas laborales, bien por iniciativa propia, o mediante directivas de la Unión Europea, a efecto de responder a las exigencias de la economía globalizada y para que el derecho del trabajo pueda seguir realizando la función de cohesión social.

SEXTA. La desregulación y la flexibilización se han reflejado en la jornada de trabajo, esencialmente en la vertiente de distribución del tiempo y horario de trabajo, que pretende que el trabajo efectivo del trabajador responda a los nuevos esquemas organizativos, de producción y productividad. 
